\title{
MONCHANIN (Jules), Mystique de l'Inde, mystère chrétien
}

Fontfroide le Haut (Saint-Clément-34), Fata Morgana, 1999. 254 p. (préface de Suzanne Siauve) (index) (coll. « Hermès », 19)

\section{André Padoux}

\section{(2) OpenEdition} Journals

Édition électronique

URL : http://journals.openedition.org/assr/20923

DOI : $10.4000 /$ assr. 20923

ISSN : $1777-5825$

Éditeur

Éditions de l'EHESS

\section{Édition imprimée}

Date de publication : 1 juin 2001

Pagination : 148-149

ISBN : 2-222-96704-X

ISSN : 0335-5985

Référence électronique

André Padoux, "MONCHANIN (Jules), Mystique de I'Inde, mystère chrétien », Archives de sciences sociales des religions [En ligne], 114 | avril-juin 2001, document 114.95, mis en ligne le 19 août 2009, consulté le 21 septembre 2020. URL : http://journals.openedition.org/assr/20923 ; DOI : https:// doi.org/10.4000/assr.20923

Ce document a été généré automatiquement le 21 septembre 2020

(c) Archives de sciences sociales des religions 


\section{MONCHANIN (Jules), Mystique de l'Inde, mystère chrétien}

Fontfroide le Haut (Saint-Clément-34), Fata Morgana, 1999. 254 p. (préface de Suzanne Siauve) (index) (coll. « Hermès », 19)

André Padoux

\section{RÉFÉRENCE}

MONCHANIN (Jules), Mystique de l'Inde, mystère chrétien, Fontfroide le Haut (Saint-

Clément-34), Fata Morgana, 1999. 254 p. (préface de Suzanne Siauve) (index) (coll.

« Hermès ", 19)

1 Cette réédition de certains textes de l'abbé J.M., rassemblés avec quelques autres qui n'avaient jamais paru, est tout à fait bienvenue, aussi bien pour rappeler le souvenir d'une personnalité exceptionnelle que pour revenir sur la difficile question de l'«adaptation » du christianisme au monde indien. J.M., en effet, prêtre lyonnais qui vint en Inde en 1939 et en repartit, malade, en 1957, pour mourir peu après en France, eut un rôle de pionnier dans l'effort entrepris depuis un demi-siècle par l'Église catholique pour se donner "un visage indien ». Après une formation de prêtre et quinze années d'apostolat dans la région lyonnaise, s'il avait étudié à l'Université la pensée indienne, il ne connaissait pas, quand il y fut envoyé, l'Inde qui allait cependant devenir son « pays d'élection ». Prêtre diocésain dans le sud de l'Inde, il tint dès l'abord - et non sans choquer les autorités ecclésiastiques locales - à mener la même vie que les pauvres de ce pays. Il voulut en même temps se mettre "à l'école des sages ", acquérant ainsi une profonde connaissance de la pensée religieuse et métaphysique de l'Inde, comme de sa mystique. Mais s'il pensa (comme l'avait fait au XVIII e siècle le P. de Nobili) qu'il lui fallait s'indianiser dans une certaine mesure pour attirer les Indiens vers la foi chrétienne, il veilla à ne jamais rien sacrifier de celle-ci à cette visée. Il différa en cela de ceux qui, surtout après lui, se voulurent moines chrétiens et hindous à la fois (pour parler comme le P. Le Saux). Cela ressort des textes que voici, échelonnés 
de 1936 à 1955: notes personnelles, conférences, articles parus dans diverses publications, où, saisissant bien ce que la pensée indienne/hindoue a de particulier et cherchant le point où celle-ci pourrait rejoindre la pensée chrétienne, il souligne aussi bien les points communs que les incompatibilités de ces deux univers. Il compare et oppose ainsi le sacrifice de la messe, qui est commémoration, au culte hindou, la puja, rite d'accueil et d'hommage à la divinité et mouvement d'identification avec elle, d'ailleurs plus culte personnel que liturgie accomplie dans un temple. Il souligne aussi la place centrale du yoga, "discipline physiologique que traverse une métaphysique ", revêtant un aspect d'«auto-déification " que, pour cela même, il juge peu adaptable dans une perspective chrétienne. Mais il ne rejette pas pour autant un yoga chrétien, dont l'esprit alors serait tout autre. Il ajoute d'ailleurs que faute d'accepter certains aspects du yoga, on ne peut aller vers l'Inde. Et de fait, de telles réserves n'ont plus cours aujourd'hui. Il y a, dans ces courts textes, des intuitions, des interrogations, essentielles. J.M. était sensible à la profondeur de la pensée indienne, à son sens du divin, mais il ne cédait pas à sa fascination. Il différait en cela (c'était, il est vrai, il y a un demi-siècle) de ceux qui l'ont suivi, tel, par exemple, le P. Le Saux, ou, encore davantage, Raimon Panikkar. C'est avec le P. Le Saux qu'il fonda en 1950, sur les rives d'une des rivières sacrées de l'Inde du sud, un ashram à l'indienne, adoptant le style de vie des renonçants indiens, revêtant la robe ocre des sannyasi, indianisant certains aspects de la liturgie. La tentative, on le sait, ne fut pas un succès. Elle ne lui survécut guère. Mais l'effort de l'Église d'acculturation à l'Inde se poursuit, la question se posant toutefois de savoir jusqu'à quel point le christianisme peut s'acculturer à l'Inde sans s'hindouiser (cf. Arch. $n^{\circ}$ 104.2). J.M. souligne ici les conditions comme les limites qu'il lui semble important de fixer à cet exercice.

2 Ce volume, par tous les points essentiels auxquels il touche, mérite tout entier lecture. Clairement présenté par Françoise Jacquin, avec une "présentation » précédemment écrite par Suzanne Siauve (1919-1975), indianiste dont J.M. avait orienté les recherches, il est bien annoté et il se complète d'un utile index. Ajoutons que, comme c'est habituellement le cas aux éditions Fata Morgana, la présentation matérielle de l'ouvrage est d'une qualité que l'on rencontre rarement aujourd'hui. 